\title{
The $\mathrm{Ba}_{10} \mathrm{~S}\left(\mathrm{VO}_{3} \mathrm{~S}\right)_{6}$ Oxysulfide: 1D-Structure and Mixed Anion Chemical Bonding
}

\author{
Sarah Nicoud ${ }^{1}$, Olivier Mentré ${ }^{1}$, Houria Kabbour ${ }^{1 *}$ \\ ${ }^{1}$ Univ. Lille, CNRS, Centrale Lille, ENSCL, Univ. Artois, UMR 8181 - UCCS - Unité de Catalyse et \\ Chimie du Solide, F-59000 Lille, France \\ *houria.kabbour@univ-lille.fr
}

\begin{abstract}
The new oxysulfide $\mathrm{Ba}_{10} \mathrm{~V}_{6} \mathrm{~S}_{7} \mathrm{O}_{18}$, that can be written as $\mathrm{Ba}_{10} \mathrm{~S}\left(\mathrm{VO}_{3} \mathrm{~S}\right)_{6}$, was prepared by solid state reaction. It crystallizes in the non-centrosymmetric $P 6_{3}$ space group with the unit cell parameters $a=18.3018(2) \AA$ and $c=8.6525(2) \AA, R_{1}=3.21 \%$. This original phase exhibits $\left(V_{3} S\right)$ units separated by $\mathrm{Ba}^{2+}$ cations, the later delimit 1D-hexagonal-like cavities filled by disordered sulfur $\mathrm{S}^{2-}$ anions and arranged into two kinds of sulfur-deficient 1D-channels. DFT calculations were employed to get insights into the chemical bonding and parameters ruling the structure, particularly the $\mathrm{V}-\mathrm{O}$ vs. $\mathrm{V}-\mathrm{S}$ bonding inside the mixed anion $\mathrm{VO}_{3} \mathrm{~S}$ tetrahedra, and the contribution of the $\mathrm{S}^{2-}$ of the cavities. The title compound can be decomposed with three components mainly interacting by ionic bonds as follows, $\mathrm{Ba}_{10} \mathrm{~V}_{6} \mathrm{~S}_{7} \mathrm{O}_{18} \rightarrow\left[\mathrm{Ba}_{10}\right]^{20+}[\mathrm{S}]^{2-}$ $\left[\left(\mathrm{VO}_{3} \mathrm{~S}\right)_{6}\right]^{18-}$, this description may pave the way to the design of other phases related to this system with adjusted band gap features. In particular, the effect of the $V(O, S)_{4} / B a$ ratio is discussed to emphasize the presence of the $[S]^{2-}$ component, in comparison with related structures such as $\mathrm{Ba}_{6} \mathrm{~V}_{4} \mathrm{O}_{5} \mathrm{~S}_{11}\left[\mathrm{Ba}_{6}\left(\mathrm{VO}_{2} \mathrm{~S}_{2}\right)_{2}\left(\mathrm{VS}_{3} \mathrm{O}\right)\left(\mathrm{VS}_{4}\right)\right]$, as it contributes strongly just below the fermi level with subsequent alteration of the band gap.
\end{abstract}

Keywords: Mixed anion, oxysulfide, oxychalcogenide, heteroleptic coordination, band gap engineering, building units, DFT, COHP 


\section{Introduction}

The search of new functional semiconductors can greatly benefits from the possibilities offered by mixed anion systems ${ }^{1}$ as shown from a number of examples, in particular considering oxychalcogenides in which the different chemical bonding related to $\mathrm{O}^{2-}$ or $\mathrm{Ch}^{2-}$ allows tuning the electronic structure. ${ }^{2-4}$ For instance, $\mathrm{LaCuOCh}(\mathrm{Ch}=\mathrm{S}$, Se and Te) phases are $p$-type wide-band-gap-semiconductors, ${ }^{5,6}$ in which the structure is formed by the stacking of ( $\mathrm{LaO})$ fluorite type layers and ( $\mathrm{CuCh}$ ) anti-fluorite layers. $\mathrm{La}_{2} \mathrm{O}_{2} \mathrm{~S}$ is another wide-band-gap layered oxysulfide and efficient phosphor, with versatile emission performances of the rareearth-doped phase. ${ }^{5,7,8}$ Here, the fluorite $\left(\mathrm{La}_{2} \mathrm{O}_{2}\right)$ slabs alternate with sulfur layers. In the later examples, the anions segregation favors a two dimensional structuration. Although $\mathrm{O}^{2-}$ and $\mathrm{S}^{2-}$ are quite different in size and chemistry, they can lead to heteroleptic coordination around a metal cation, i.e. mixed anion building units, such as in the polar phase $\mathrm{CaOZnS}$ with distorted $\mathrm{ZnS}_{3} \mathrm{O}$ tetrahedron $(T d)$. A strongly polar structure is stabilized leading to finely tunable photoluminescent and mechanoluminescent properties, after $\mathrm{Mn}$ doping at the $\mathrm{Zn}$ site ${ }^{6}$ For similar reasons the polar $\mathrm{BaGeSe}_{2} \mathrm{O}$ phase, another rather scarce example, displays large nonlinear-optical response compared to the oxide analogue due to cooperative arrangement of the distorted mixed anion $\mathrm{GeO}_{2} \mathrm{Se}_{2}$ building units. ${ }^{9}$ In all these examples the polar $\mathrm{MO}_{4-\mathrm{x}} \mathrm{Ch}$ groups are the key structural entity for the generation of striking properties with mechanisms relying on the anionic diversity.

Other oxychalcogenides illustrate well the potentialities of band gap engineering from an heteroleptic coordination at the transition metal site, such as the $A_{3} \mathrm{~V}\left(\mathrm{O}_{4-\mathrm{x}} \mathrm{S}_{\mathrm{x}}\right)_{3}\left(A=\mathrm{Na}^{+}, \mathrm{K}^{+}\right.$, $x=0,1,2,3$ or 4 ) phases, made of Alkaline cations $A^{+}$and $\mathrm{V}(\mathrm{O}, \mathrm{S})_{4} T d$ with different $\mathrm{O} / \mathrm{S}$ ratios leading to colors ranging from yellow to deep red upon increased sulfur content, $\mathrm{VO}_{4} \rightarrow \mathrm{VO}_{3} \mathrm{~S}$ $\rightarrow \mathrm{VO}_{2} \mathrm{~S}_{2} \rightarrow \mathrm{VS}_{4}{ }^{10,11} \ldots$. Besides alkaline elements, several of the later $T d$ cohabit together with $\mathrm{Ba}^{2+}$, so far in one remarkable compound, $\mathrm{Ba}_{6} \mathrm{~V}_{4} \mathrm{O}_{5} \mathrm{~S}_{11}$, i.e. $\mathrm{Ba}_{6}\left(\mathrm{VO}_{2} \mathrm{~S}_{2}\right)_{2}\left(\mathrm{VS}_{3} \mathrm{O}\right)\left(\mathrm{VS}_{4}\right)$. The later exhibits three of those mixed oxygen/sulfur or sulfur $T d$ simultaneously $\left(\mathrm{VOS}_{3}, \mathrm{VO}_{2} \mathrm{~S}_{2}\right.$ and $\left.V \mathrm{~S}_{4}\right)$. A cooperative polar arrangement of $\mathrm{VO}_{3} \mathrm{~S}$ units is also found in the $\mathrm{Ba}_{3} \mathrm{~V}_{2} \mathrm{~S}_{4} \mathrm{O}_{3}$ phase, a quasi1D S=1 magnet and strongly correlated Mott insulator, ${ }^{12}$ where $\left(\mathrm{VS}_{3}\right)_{\infty}$ chains built from facesharing $\mathrm{V}^{3+} \mathrm{S}_{6}$ octahedra may be replaced by $\left(\mathrm{CrS}_{3}\right)_{\infty}$ chains (see reference $12 \mathrm{~b}$ ) and are separated by $\mathrm{Ba}^{2+}$ and $\mathrm{VO}_{3} \mathrm{~S}$ entities. Note that these phases represent the unique oxysulfide cases within the broad series of isotypic chalcogenides $A_{3}\left(M_{1-x} S_{3}\right)\left(X S_{4}\right)(A=$ rare earth ; $M=F e$, 
$\mathrm{Cu}, \ldots ; \mathrm{X}=\mathrm{Si}, \mathrm{Ge} . .).) .{ }^{13}$ The chains provide tunable low dimensional magnetic/electronic properties within this series.

Here, we present a new structural type in which barium is associated with $\mathrm{VO}_{3} \mathrm{~S} T d$ as well as isolated sulfur atoms which is rather uncommon. This orange phase exhibits an experimental bandgap of $2.25 \mathrm{eV}$, that we comment in terms of electronic structure and compare to the series $A_{3}\left(\mathrm{VO}_{3} \mathrm{~S}\right)\left(A=\mathrm{Na}^{+}, \mathrm{K}^{+}\right)$and to the phase $\mathrm{Ba}_{6}\left(\mathrm{VO}_{2} \mathrm{~S}_{2}\right)_{2}\left(\mathrm{VS}_{3} \mathrm{O}\right)\left(\mathrm{VS}_{4}\right)$. The electronic structure in this group of material should allow identifying interesting features and key parameters for the design of new optically tuned semi-conductors.

\section{Experimental section}

Synthesis: Single crystals of $\mathrm{Ba}_{10} \mathrm{~V}_{6} \mathrm{~S}_{7} \mathrm{O}_{18}$ were initially found in a preparation based on the precursors $\mathrm{BaO} / \mathrm{MnO} / \mathrm{V} / \mathrm{S}$ in the ratio 3:1:1:3. The later were mixed and thoroughly grounded in an agate mortar before being pressed into pellets and heated in evacuated sealed quartz tube. The preparation was carried out in an Argon dry-glove box. The temperature program consisted in heating at a rate of $50^{\circ} \mathrm{C}$ up to at $800^{\circ} \mathrm{C}$ for 96 hours then cooling at $50^{\circ} \mathrm{C} / \mathrm{h}$ down to room temperature. The final product was a mixture of various phases including the title compound. We attempted to synthesize a single phase material from a mixture of the precursors $\mathrm{BaS} / \mathrm{BaO} / \mathrm{V}_{2} \mathrm{O}_{5}$ in the ratio 7:3:3 grounded in an agate mortar before being pressed into pellets. The preparation was carried out in an Argon dry-glove box and heated in an evacuated sealed quartz tube at various temperatures $\left(600\right.$ to $\left.900^{\circ} \mathrm{C}\right)$ to determine the best protocol. A rate of $50^{\circ} \mathrm{C}$ up to the synthesis temperature was applied and the targeted temperature maintained for 96 hours. The products were grounded and pressed into pellets for additional heating using the same conditions, but no significant improvement of the purity was observed. The same observation was made when varying the cooling protocol.

The powder X-ray diffraction pattern was collected on a Bruker D8 diffractometer equipped with a linear detector Lynxeye $\left(\mathrm{Cu}_{\kappa \alpha}\right)$ in Bragg-Brentano geometry at room temperature.

X-ray diffraction on single crystals was performed on an APEX DUO diffractometer equipped with a bi-dimensional CCD 4K detector and a Mo K $\alpha$ source.

For the study of $\mathrm{Ba}_{10} \mathrm{~V}_{6} \mathrm{~S}_{7} \mathrm{O}_{18}$, DFT calculations were carried out by employing the projector augmented wave (PAW) ${ }^{14,15}$ method encoded in the Vienna ab initio simulation package $(\text { VASP })^{16}$ and the generalized gradient approximation of Perdew, Burke and Ernzerhof (PBE) 
for the exchange-correlation functionals. ${ }^{17}$ The full geometry optimizations were carried out using a plane wave energy cutoff of $550 \mathrm{eV}$ and $20 \mathrm{k}$ points in the irreducible Brillouin zone. It converged with residual Hellman-Feynman forces on the atoms smaller than $0.03 \mathrm{eV} / \AA$ and led to a good match with the experimental structure, i.e. within a reasonable error expected for the GGA method. The relaxed structure was used for calculations of the electronic structure. For the later, the plane wave cutoff energies of $550 \mathrm{eV}$ and the threshold of selfconsistent-field energy convergence of $10^{-6} \mathrm{eV}$ were used, with $128 \mathrm{k}$ points in the irreducible Brillouin Zone. By comparison, for $\mathrm{Ba}_{6} \mathrm{~V}_{4} \mathrm{~S}_{11} \mathrm{O}_{11}, 550 \mathrm{eV}, 10^{-6} \mathrm{eV}$ and $24 k$ points were used, respectively. Then, for the title phase, a COHP (Crystal Orbital Hamilton Population) analysis was carried out in the framework of the LOBSTER software ${ }^{18-20}$.

Scanning electron microscopy (SEM) experiments and EDX analysis were carried out on a Hitachi S400N.

UV-Visible measurements: The absorbance of the sample was measured from 250 to $800 \mathrm{~nm}$ on a Perkin Elmer Lambda 650 device.

\section{Results and Discussion}

Crystal structure: After the selection of a suitable orange single crystal, XRD data collection was carried at room temperature using $\mathrm{MoK}_{\alpha}$ radiation $(\lambda=0.71073 \AA$ ) . The details of data collection strategy and refinement parameters are reported table 1. The structure was solved in the P6 $6_{3}$ space group with the unit cell parameters $a=18.3018(6) \AA$ and $c=8.6525(4) \AA$, $\mathrm{R}=0.0321$, by Charge Flipping method, and least-squares refined using the JANA2006 Software package ${ }^{21}$, leading to the formula $\mathrm{Ba}_{10} \mathrm{~V}_{6} \mathrm{~S}_{7} \mathrm{O}_{18}$ in good agreement with the EDS analysis from which the average ratio 10/5.8/6.3 is found for Ba/V/S (see also S3 for a SEM image and a picture of the orange colored sample). Four twinned domains with similar weight (ca. 25\%) related to the $6 / \mathrm{mmm}$ Laue class and racemic components were taken in account. The atomic positions and anisotropic displacement parameters are reported in tables 2 and 3 . It shows disconnected $\mathrm{VO}_{3} \mathrm{~S}$ tetrahedrons separated by $\mathrm{Ba}^{2+}$ cations leading to the creation of an open framework. Here, the $\mathrm{Ba}^{2+}$ cations delimit two kinds of $1 \mathrm{D}$ channel with face-sharing $\mathrm{Ba}_{6}$ 
octahedral cavities that accommodate or not additional sulfur anions $\mathrm{S}^{2-}$. Besides, there are three independent sites of Vanadium atoms in $\mathrm{VO}_{3} \mathrm{~S}$ coordination with 1.631 to $1.790 \AA$ typical V-O distances and 2.145 to $2.195 \AA$ A typical V-S distances, see table 4. The barium cations array presents a certain degree of disorder with two satellite positions for $\mathrm{Ba} 4$ and $\mathrm{Ba} 5$ with complementary occupancies, i.e. Ba4a/4b (occ. 0.914(2)/0.086(2)) and Ba5a/5b (occ. $0.83(2) / 0.17(2))$. Those barium atoms are among the cations surrounding sulfur atoms in the cavities. Accordingly, the S4 and S5 sulfur atoms isolated in those hexagonal-like cavities are also partially occupied with a total S occupancy restrained for electroneutrality. Then two kinds of channels coexist with partially occupied $\mathrm{BaS}_{6}$ octahedra. In the so-labelled "channel $1 "$, S4 (occ. $0.852(12)$ ) atoms form infinite chains of those octahedra with local vacancies responsible for the $\mathrm{Ba} 5 \mathrm{a} / \mathrm{Ba} 5 \mathrm{~b}$ split. Here the next anionic shell around $\mathrm{S}$ consist of quasi planar $\mathrm{O}_{3} \mathrm{~S}_{3}$ polyhedra with compatible S--S and S--O distances, see figure $1 \mathrm{c}$. In the so-labelled "channel 2", partially occupied S5 centered (occ. 0.648(12)) and empty Ba6 octahedra alternate leading to a strongly lacunar chain, $c a .1 / 3^{\text {rd }}$ occupied. It is clear from figure 1 , that the half ordered vacancies $(\square)$ result from the $\square--S_{6}$ second anionic shell (involved in $\mathrm{VO}_{3} S$ units) with ideal $\square-$-S distances between 3.1 and $3.3 \AA$, i.e. too short for the participation of a central S anion. On the opposite, S5 show an $\mathrm{S}-\mathrm{O}_{6}$ coordination with correct distances. Thus, it turns out that the orientation of the $\mathrm{VO}_{3} \mathrm{~S}$ groups rule the occupancy of the $\mathrm{BaS}_{6}$ cavities and

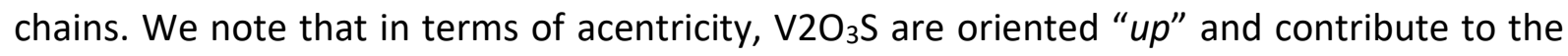
total dipolar momentum, while $\mathrm{V}_{1} \mathrm{O}_{3} \mathrm{~S}$ and $\mathrm{V}_{3} \mathrm{O}_{3} \mathrm{~S}$ almost cancel each other.

Comparison with other related structural types: The titled compound is original by the copresence of $\mathrm{S}^{2-}$ isolated anions in channels and $\left(\mathrm{VO}_{3} \mathrm{~S}\right)^{3-}$ mixed anion $\mathrm{Td}$. To get further insights on the intrinsic $\mathrm{VO}_{3} \mathrm{~S}$ bonding scheme, it is interesting to discuss the $\mathrm{A}_{3}\left(\mathrm{VO}_{4-\mathrm{x}} \mathrm{S}_{\mathrm{x}}\right)\left(\mathrm{A}=\mathrm{Na}^{+}, \mathrm{K}^{+}\right)$ ionic examples. These compounds, although all consisting in simple $T d$ separated by $A^{+}$ cations, crystallize in several different space groups depending on the $A^{+}$cations and the $\mathrm{O} / \mathrm{S}$ anions ratio. For instance, $\mathrm{Na}_{3} \mathrm{VO}_{3} \mathrm{~S}^{22}$ phase exhibits an orthorhombic cell in the noncentrosymmetric space group $R 3 \mathrm{c}$ due to the polar cooperative alignment of the $\mathrm{VO}_{3} \mathrm{~S}$ units as found in our compound. A description of the tetrahedra packing and relative orientation in different phases is given in the corresponding literature (references 10-11, 22).

Dealing with the sulfur cavities arranged in chains found in the titled compound, similar ones are found for instance in the sulfide $\mathrm{Ba}_{9} \mathrm{Fe}_{3} \mathrm{~S}_{11}\left(\mathrm{~S}_{2}\right)_{2},{ }^{23}$ a high pressure polymorph of $\mathrm{Ba}_{3} \mathrm{FeS}_{5}$. In 
the later, face-sharing $\mathrm{FeS}_{6}$ octahedra are stabilized in chains and are separated by barium atoms arranged in a manner that delimit rather similar cavities than in our phase. In particular $\mathrm{Ba}_{6}$ octahedra sharing faces are also found and are occupied by sulfur atoms which are either isolated $\mathrm{S}^{2-}$ anions or involved in a disulfide pair $\left(\mathrm{S}_{2}\right)^{2-}$.

Powder synthesis: Our attempts to synthesize the title phase in a pure form led to its formation but always accompanied by impurities, at least in our solid state conditions although varying the temperature and the cooling protocol. In particular, the pure phase seems to be hampered by the apparition of the stable vanadate phase $\mathrm{Ba}_{3}\left(\mathrm{VO}_{4}\right)_{2}$. Nevertheless, we have performed a multiphase Rietveld refinement using Jana2006 (ref. 21) based on the single crystal determined structure, see figure 2 . We find the ratio $0.634(3) / 0.366(4)$ for the title phase/impurity, with reasonable reliability factors $\left(R_{o b s}=4.98 \%, \mathrm{wR}_{\mathrm{obs}}=4.75 \%, \mathrm{R}_{\mathrm{all}}=5.09 \%\right.$, $w R_{a l l}=4.77 \%$ and $G O F=1.38$ ). If our studies show that the title phase can be formed in a large amount, the multi-phased sample makes difficult physical properties measurements requiring powder samples. However, UV-Visible optical measurements were possible as the contribution of the reported vanadate (colorless) is well established in the literature. ${ }^{24}$ Figure 3 shows the optical measurement after a Kubelka-Munk ${ }^{25}$ transformation, where both the band gap of our phase pointed as $\sim 2.25 \mathrm{eV}$ and of $\mathrm{Ba}_{3}\left(\mathrm{VO}_{4}\right) \sim 3.8 \mathrm{eV}$ can be evidenced. The main challenge is to avoid the formation of $\mathrm{Ba}_{3}\left(\mathrm{VO}_{4}\right)_{2}$ using alternative synthetic methods, which is out of the scope of this work. However, DFT calculations allow having some insights on the expected properties of this phase.

\section{Chemical bonding - Theoretical calculations:}

Model used for simulation: Dealing with a slightly disordered crystal structure on some of the barium and sulfur sites with partial occupancies, we approximate an ordered model that preserves the composition $\mathrm{Ba}_{10} \mathrm{~V}_{6} \mathrm{~S}_{7} \mathrm{O}_{18}$ by lowering the symmetry to $P 3$, see table in $\mathrm{S} 1$. The satellite positions $\mathrm{Ba} 4 \mathrm{a}$ / $\mathrm{Ba} 4 \mathrm{~b}(\mathrm{Ba} 5 \mathrm{a} / \mathrm{Ba} 5 \mathrm{~b})$ with complementary occupancies were reduced to one fully occupied position by selecting the largest occupied Ba4a (Ba5a) initially. In the same way, the partially occupied S4 (occ. 0.852 in a $2 b$ site) and S5 (occ. 0.648 in a $2 a$ site) sulfur sites in the cavities were ordered as follows: S4 site (channel 2, in which the $\mathrm{Ba}_{6}$ octahedra forming the chain alternate as occupied by S4 or vacant) was approximated to be fully occupied while S5 (channel 1, in which the Ba6 octahedra forming the chain contain all S5 
sites) was approximated half occupied in order to introduce vacant sites as found in channel 1. For the later, as allowed in the $P 3$ subgroup with the splitting of the $2 \mathrm{a}(0,0, \mathrm{z})$ site into two $(0,0, z)$ and $(0,0, z+1 / 2)$ sites, a single one $(0,0,0.0130)$ was filled in our model. This choice for the channels represents a necessary approximation to handle our DFT calculations on this phase without further decreasing the symmetry or supercell ordering along $c$. We assume that the high calculation cost of these alternative models is not relevant in this study. The full optimization led to a reasonable structure compatible with the experimental one after close inspection of the structural features and interatomic distances, see table 4 . The relaxed ordered structure was used to calculate the electronic structure as detailed below. The total DOS exhibits a band gap of $\sim 1.91 \mathrm{eV}$, thus a good agreement is obtained regarding the orange color of our crystals and the experimental band gap (2.25 eV) with a typical underestimation usually found from GGA calculations. The calculated band gaps (eV) for the sodium vanadate and thio-vanadates with increasing sulfur ratio were reported in the literature as follows: $\mathrm{Na}_{3}\left(\mathrm{VO}_{4}\right)(3.55) \rightarrow \mathrm{Na}_{3} \mathrm{VO}_{3} \mathrm{~S}(3.05) \rightarrow \mathrm{Na}_{3} \mathrm{VO}_{2} \mathrm{~S}_{2}(2.5) \rightarrow \mathrm{Na}_{3} \mathrm{VOS}_{3}(1.93) \rightarrow \mathrm{Na}_{3}\left(\mathrm{VS}_{4}\right)$ (1.67). For the potassium analogues the value decreases as follows from $\mathrm{K}_{3} \mathrm{VO}_{3} \mathrm{~S}$ to $\mathrm{K}_{3} \mathrm{VS}_{4}: 3.15 \rightarrow 2.55 \rightarrow$ $2.10 \rightarrow 1.80$, i.e. slightly higher values than for the Na-phases. Although a different method was used, FP-LAPW calculations with the code Wien2k, the similar Generalized Gradient Approximation (GGA) should lead to the same order of underestimation of the band gap than our calculations. It places our phase close to the values for $\mathrm{Na}_{3} \mathrm{VOS}_{3}$ and far from the phases containing the same $\mathrm{VO}_{3} \mathrm{~S}$ thio-oxo-vanadate anion, highlighting the effect of isolated $\mathrm{S}^{2-}$ species in the cavities that decrease the band gap. ${ }^{10,11}$

Density of States and COHP: The total and projected densities of states are represented in figure 3. First, focusing on the $\mathrm{VO}_{3} \mathrm{~S}$ units, the Vanadium $3 d$ states are lying in the conduction band higher than $2 \mathrm{eV}$ with the highest contribution between $2 \mathrm{eV}$ and $4 \mathrm{eV}$ approximatively. In the VB, the $3 d$ states of Vanadium are hybridized with $\mathrm{O} 2 p$ and $\mathrm{S} 3 p$ states (see also COHP). The $\mathrm{V} 3 \mathrm{~d}$ states contribution is mainly centered around -4 to $-3 \mathrm{eV}$. The $\mathrm{O} 2 p$ strongly contribute in the same region although found up to the very top of the VB. The S $3 p$ states however, although contributing in the same region than Vanadium in the VB, are more present in the top of the VB, especially a sharp density of states peak is found around $-1 \mathrm{eV}$. For comparison, it is interesting to mention our calculations for $\mathrm{Ba}_{6} \mathrm{~V}_{4} \mathrm{O}_{5} \mathrm{~S}_{11}$, i.e. $\mathrm{Ba}_{6}\left(\mathrm{VO}_{2} \mathrm{~S}_{2}\right)_{2}\left(\mathrm{VS}_{3} \mathrm{O}\right)\left(\mathrm{VS}_{4}\right)$. The DOS projected on the various $\mathrm{Td}$ units show their tendency to 
contribute higher in the VB when increasing the sulfur content (from $\mathrm{VO}_{3} \mathrm{~S} \rightarrow \mathrm{VS}_{4}$ ), see figure 4.

In addition, the Crystal Orbital Hamiltonian Population (COHP) pictures the bonding nature and strength, see figure 5. Here, it is interesting to compare V-O and V-S bonding within the $\mathrm{VO}_{3} \mathrm{~S}$ entity of $\mathrm{Ba}_{10} \mathrm{~V}_{6} \mathrm{~S}_{7} \mathrm{O}_{18}$. Net bonding character is found for both, and more covalent bonding is expected for $\mathrm{V}-\mathrm{S}$ regarding electronegativities: $3.44,2.58$, and 1.63 , for $\mathrm{O}, \mathrm{S}$ and $\mathrm{V}$, respectively. Accordingly, V-S bonding states are present just below the Fermi level while bonding V-O states are predominant lower in the VB. More into details, the bonding states for $\mathrm{V}-\mathrm{O}$ are found in the lower VB region with a large contribution centered on $\sim-3.5 \mathrm{eV}$. Oppositely, V-S bonding is of bonding nature in all VB with higher contribution just below the Fermi level, while in the same region a small but significant amount of antibonding interactions are found for $\mathrm{V}-\mathrm{O}$ (from $\mathrm{E}_{\mathrm{F}}$ down to about $-1 \mathrm{eV}$ ). Upper the Fermi level, both $\mathrm{V}$ $\mathrm{O}$ and $\mathrm{V}-\mathrm{S}$ interactions are found antibonding.

Now, focusing on channels and species building them, we can make the following observations: 1 ) the $\mathrm{S}^{2-}$ species inside the channels exhibit more localized states (regarding the $3 p$ states at the top of the VB). 2) At the very top of the VB, they are the main contributors just below the fermi level, while $\mathrm{S}^{2-}$ involved in $\mathrm{VO}_{3} \mathrm{~S}$ tetrahedron are present in a wider range and slightly below (see above). 3) In particular one sharp peak is found in the vicinity of the Fermi level $\sim 0 \mathrm{eV}$ (last states occupied, Valence Band Maximum-VBM) and a second $\sim-0.4 \mathrm{eV}$ for sulfur atoms located in channels 1 (S5) and 2 (S4), respectively. This is also well visible on the band structure in which very flat bands are found just below the Fermi level, see S1.

The strength of the bonding of this $\mathrm{S}^{2-}$ anions with $\mathrm{Ba}$ is depicted by the (integral) ICOHP absolute values, i.e. average $\operatorname{ICOHP}_{(\mathrm{Ba}-\mathrm{S})} \sim-1.26 \mathrm{eV}$, and is net bonding although rather low. Here, the channels' species are weakly interacting with the opened framework. Those $\mathrm{S}^{2-}$ species seems to dictate the VBM nature. In particular by further decreasing the band gap width compared to $A_{3}\left(\mathrm{VO}_{3} \mathrm{~S}\right)$ exempt of such sulfur atoms in channels. Such features are found in recent examples in the chalcogenide system $\mathrm{Ba} / M / \mathrm{S}(M=\ln , \mathrm{Ga})$, in particular in $\mathrm{Ba}_{12} \ln _{4} \mathrm{~S}_{19}$ where both isolated $\mathrm{S}^{2-}$ and disulfide pairs $\left(\mathrm{S}_{2}\right)^{2-}$ species are found in similar face-sharing $\mathrm{Ba}_{6}$ octahedra forming pseudo chains figure $6 \mathrm{~d}$. The later corresponds to oligomers of seven faceshared octahedra terminated by corner-shared octahedra while our compound exhibits genuine 1D-cavities. Although the disulfide pairs determine the band gap since their contributions to the electronic structure is found both at the top of the VB and bottom of the 
$\mathrm{CB}$, the isolated $\mathrm{S}^{2-}$ are also strongly contributing at the top of the $\mathrm{VB} \cdot{ }^{26} \mathrm{It}$ is interesting noting that these phases were obtained using an excess of sulfur in the synthetic process. Such situation with disulfide pairs (only) determining the band gap is also well described for the phase $\mathrm{Ba}_{2} \mathrm{~F}_{2}\left(\mathrm{~S}_{2}\right) .{ }^{27}$ Although the two later phases are structurally different from the title compound, they show isolated sulfur species with determinant contributions to the electronic structure around the Fermi level as found in our compound.

Actually the formula of the title compound can be decomposed with three ionic interacting components as follows, $\mathrm{Ba}_{10} \mathrm{~V}_{6} \mathrm{~S}_{7} \mathrm{O}_{18} \rightarrow\left[\mathrm{Ba}_{10}\right]^{20+}\left[\left(\mathrm{VO}_{3} \mathrm{~S}\right)_{6}\right]^{18-}[\mathrm{S}]^{2-}$. It is interesting to highlight the role of the $A(A=$ alkaline, alkaline-earth) cation in the structure on the stabilization of an edifice with $\mathrm{VO}_{3} \mathrm{~S}$ alone associated to it or with additional structural elements. For both steric and charge balance reasons, $\mathrm{Ba}^{2+}$ (compared to $\mathrm{Na}^{+}$or $\mathrm{K}^{+}$) lead to the accommodation of an excess of sulfur atoms in channels considering $\mathrm{VO}_{3} \mathrm{~S}$ tetrahedra while $\mathrm{Ba}^{2+}$ is combined with $\mathrm{VO}_{4} \mathrm{~S}_{4-\mathrm{x}}\left(\mathrm{x}=\right.$ integer) units only in the case of $\mathrm{Ba}_{6} \mathrm{~V}_{4} \mathrm{~S}_{11} \mathrm{O}_{5}\left(\mathrm{VO}_{3} \mathrm{~S}, \mathrm{VS}_{4}, \mathrm{VO}_{2} \mathrm{~S}_{2} T d\right)$ and $\mathrm{Ba}_{3}\left(\mathrm{VO}_{4}\right)_{2}$ $\left(\mathrm{VO}_{4} T d\right)$. In more details intuitive parameters that might rule the structure (entities, isolated anions or not ...) in those systems can be discussed.

Besides the balance between anions and cations and the ratio $\mathrm{O}^{2-} / \mathrm{S}^{2-}$, the interplay between the $\mathrm{Ba}^{2+} /\left(\mathrm{VO}_{x} \mathrm{~S}_{\mathrm{y}}\right)^{3-}$ ratio is of course of primary importance. For $\mathrm{V} / \mathrm{Ba}<2 / 3$, the deficiency of negative charges leads to the accommodation of excess sulfur anions $\mathrm{S}^{2-}$, which is the case of our compound with $\mathrm{V} / \mathrm{Ba}=0.6$. Several compositions will be further tested in the prospection of this complex phase diagram. In contrast, In the $\left[\left(\mathrm{VO}_{x} \mathrm{~S}_{\mathrm{y}}\right)^{3-}-3 / 2 \mathrm{Ba}^{2+}\right]$ binary system (i.e. $\mathrm{V} / \mathrm{Ba}$ $=2 / 3$ ), only two phases are reported namely $\mathrm{Ba}_{3}\left(\mathrm{VO}_{4}\right)_{2}$ and $\mathrm{Ba}_{6}\left(\mathrm{VO}_{2} \mathrm{~S}_{2}\right)_{2}\left(\mathrm{VS}_{3} \mathrm{O}\right)\left(\mathrm{VS}_{4}\right)$ which adopt different arrangements. Then we tried to synthesize other $\mathrm{O} / \mathrm{S}$ compositions such as $\mathrm{Ba}_{3}\left(\mathrm{VO}_{3} \mathrm{~S}\right)_{2}$, but no evidence of its formation could be observed. It highlights the necessary steric agreement between sizeable $\left(\mathrm{VO}_{\mathrm{x}} \mathrm{S}_{\mathrm{y}}\right)^{3-}$ groups and large $\mathrm{Ba}^{2+}$ cations for stable crystal structure. However, several metastable phases requiring specific synthetic routes out of the scope of this paper may be designed.

\section{Conclusion}


The new oxysulfide $\mathrm{Ba}_{10} \mathrm{~V}_{6} \mathrm{~S}_{7} \mathrm{O}_{18}$ crystallizes in the non-centrosymmetric $P 6_{3}$ space group. Its original structure exhibits mixed anion building units, i.e. $\mathrm{VO}_{3} \mathrm{~S}$ tetrahedra, which are disconnected from each other and separated by $\mathrm{Ba}^{2+}$ cations. In addition the $\mathrm{Ba}^{2+}$ cations define channels by forming 1D-chains of $\mathrm{Ba}_{6}$ octahedra, the octahedra are all occupied by $\mathrm{S}^{2-}$ anions in channel 1 while vacant sites are found in channel 2. Both the presence of heteroleptic tetrahedra and $\mathrm{S}^{2-}$ isolated in channels are rather uncommon. A DFT study, in particular the density of states and crystal orbital Hamilton population (COHP), allowed rationalizing the band gap with respect to the different anions of the structure: $\mathrm{S}^{2-}$ from the $\mathrm{VO}_{3} \mathrm{~S}$ units, isolated $\mathrm{S}^{2-}$ and $\mathrm{O}^{2-}$. We found that the isolated $\mathrm{S}^{2-}$ species seems to dictate the top of the valence band nature thus further decreasing the band gap width compared to the sulfur from the $\mathrm{VO}_{3} \mathrm{~S}$ entities. We show that the title compound can be described as $\mathrm{Ba}_{10} \mathrm{~V}_{6} \mathrm{~S}_{7} \mathrm{O}_{18} \rightarrow$ $\left[\mathrm{Ba}_{10}\right]^{20+}[\mathrm{S}]^{2-}\left[\left(\mathrm{VO}_{3} \mathrm{~S}\right)_{6}\right]^{18-}$, this description should pave the way to the design of band gap tuned phases. Finally, the combination of polarity and of original electronic structure features around the band gap in our phase should be at the origin of interesting properties that will be investigated in future work.

Supporting Information: The Supporting Information contain the unit cell parameters and atomic coordinates of the optimized structure (Table S1), the bands structure (Figure S1), a MEB image and a picture of the sample (Figure S2).

\section{Crystal structure report}

CCDC 1871321 contains the supplementary crystallographic data for this paper. The data can be obtained free of charge from The Cambridge Crystallographic Data Centre via $\underline{\text { www.ccdc.cam.ac.uk/structures." }}$

\section{Acknowledgments}

This work was carried out under the framework of the ANR project ANION-CO (12-JS08-0012). X-Rays Diffractometers are funded by Région NPDC, FEDER, CNRS and MESR. E. Weldekidan is thanked for technical support. The regional computational cluster supported by Lille University, CPER Nord-Pas-de-Calais/CRDER, France Grille CNRS and FEDER is thanked for providing computational resources. 


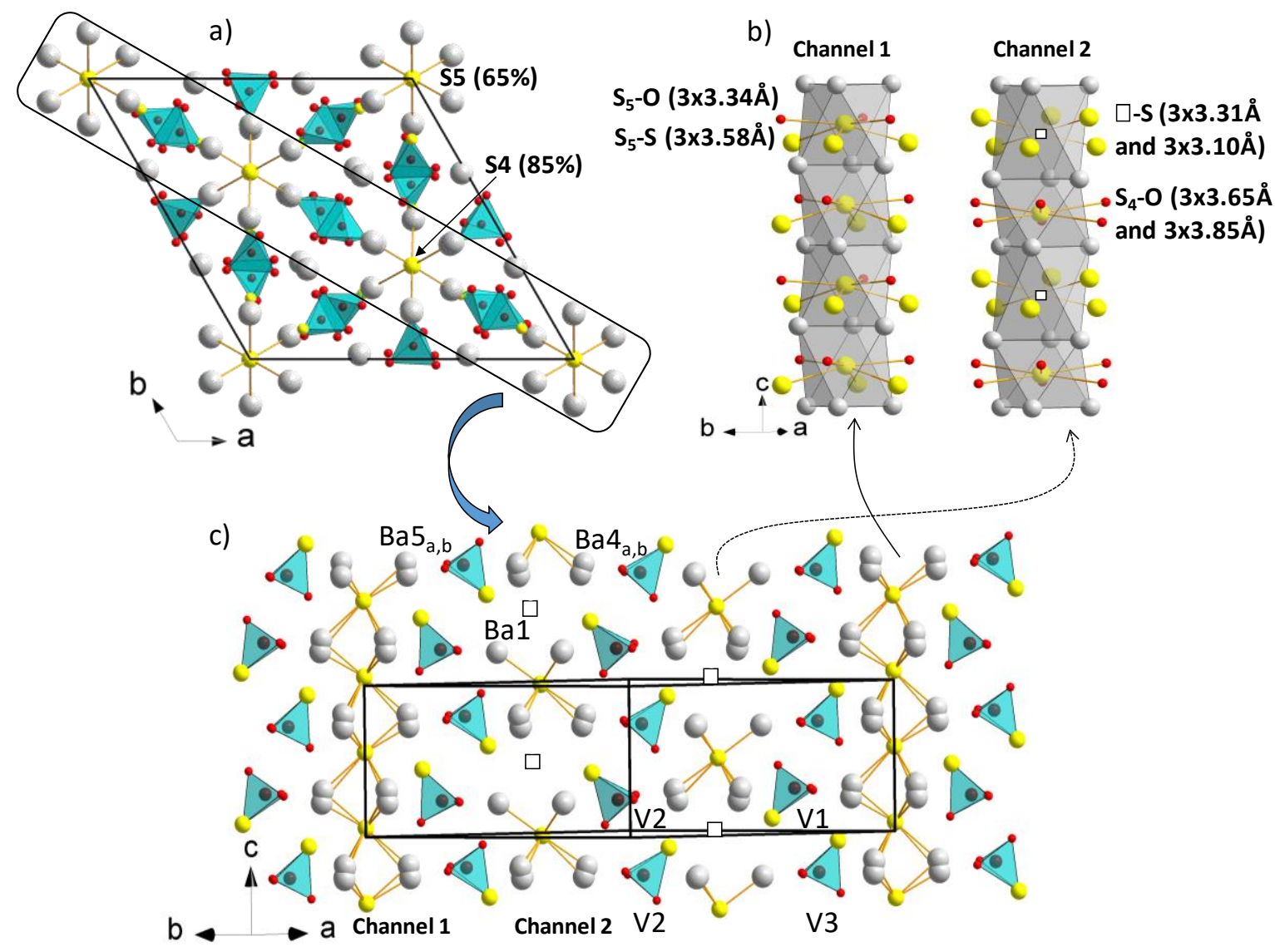

Figure 1. a) Structure of the titled compound $\mathrm{Ba}_{10} \mathrm{~V}_{6} \mathrm{~S}_{7} \mathrm{O}_{18}$ with $\mathrm{Ba}, \mathrm{S}$, and $\mathrm{O}$ represented in grey, yellow and red while the $\mathrm{VO}_{3} \mathrm{~S}$ tetrahedra are represented in blue. b) View of the channels 1 and 2 along $c$ with a polyhedral representation, the vacancies are indicated with white squares. c) View of the structure cut shown in a). 


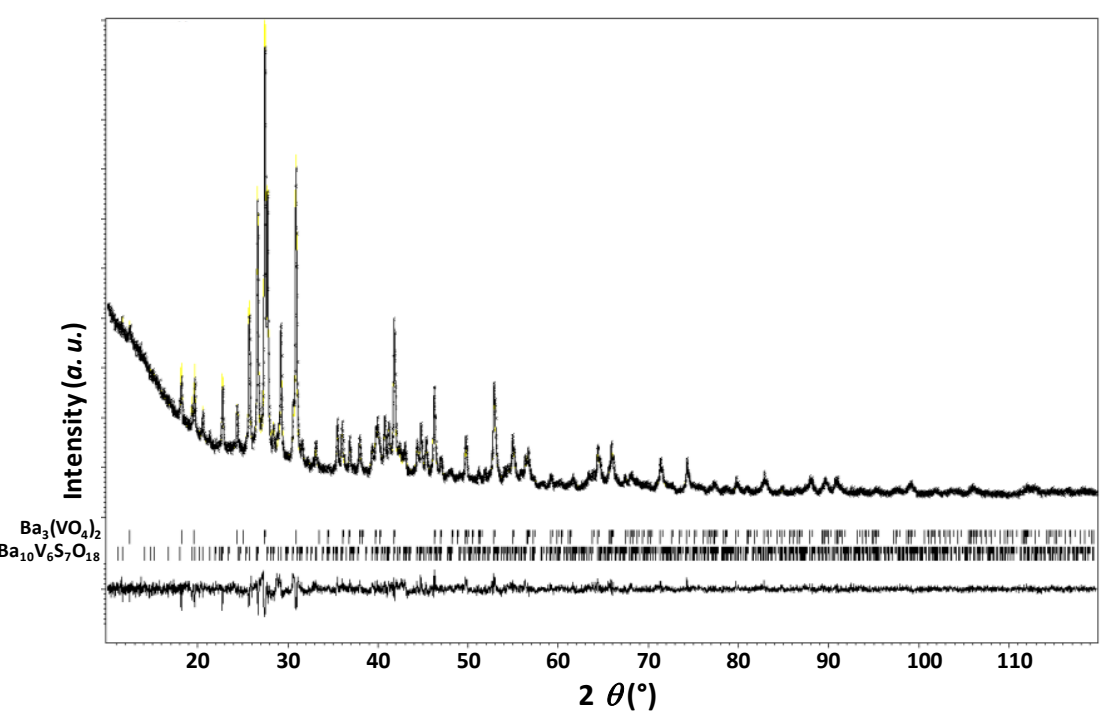

Figure 2. Multiphase Rietveld refinement of $\mathrm{Ba}_{10} \mathrm{~V}_{6} \mathrm{~S}_{7} \mathrm{O}_{18}$ with the impurity $\mathrm{Ba}_{3}\left(\mathrm{VO}_{4}\right)_{2}$ performed with the software Jana2006. The bottom curve is the difference between the experimental and calculated intensities. The small marks correspond to the Bragg peaks positions for $\mathrm{Ba}_{10} \mathrm{~V}_{6} \mathrm{~S}_{7} \mathrm{O}_{18}$ and the impurity $\mathrm{Ba}_{3}\left(\mathrm{VO}_{4}\right)_{2}$. 

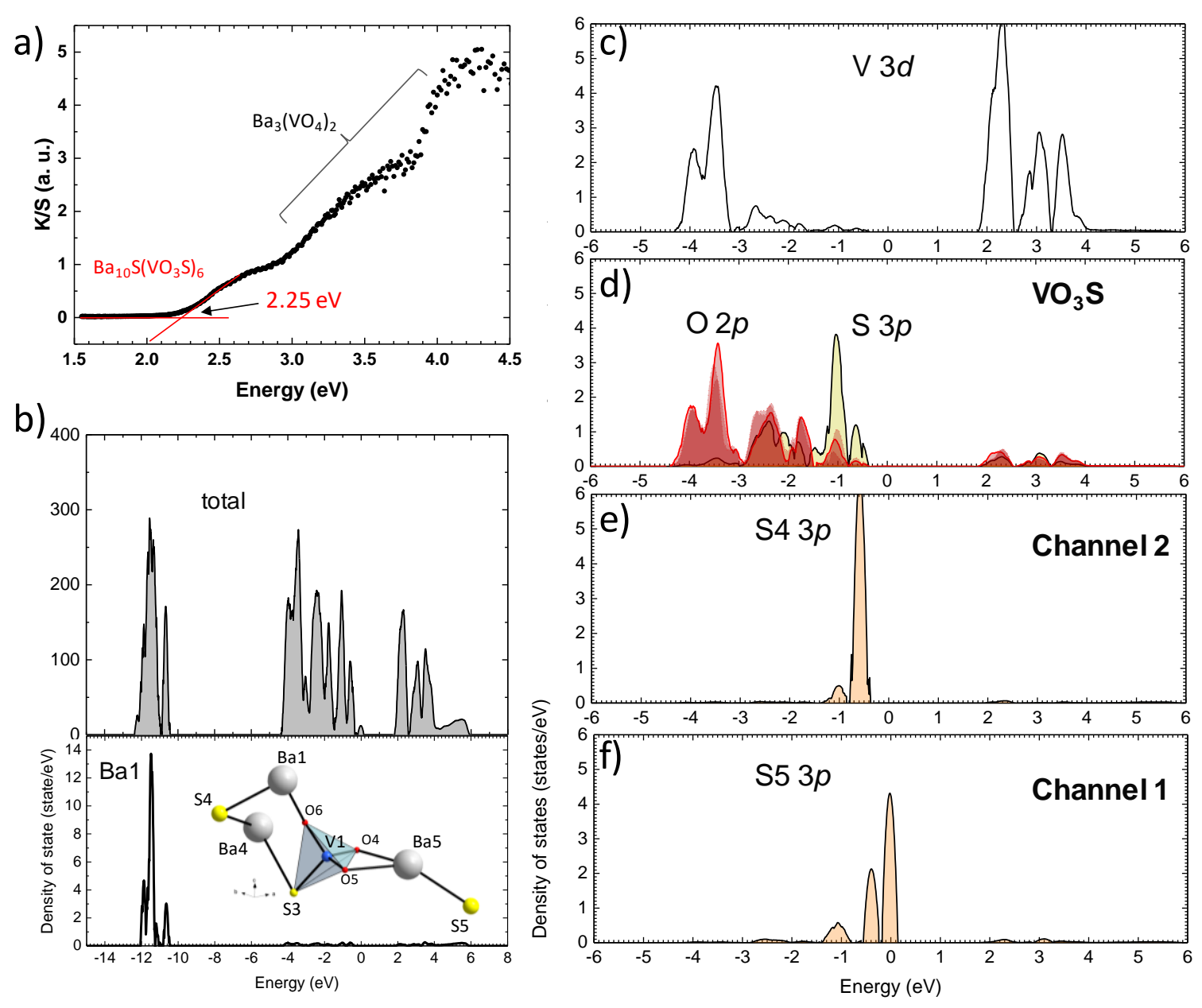

Figure 3. Optical measurements represented after a Kubelka-Munk transformation, the contribution of $\mathrm{Ba}_{3}\left(\mathrm{VO}_{4}\right)_{2}$ is shown, and the band gap of the title phase is determined as $2.25 \mathrm{eV}$. b) Total density of states and density of states projected on one Barium atom (Ba1), the other Ba atoms having similar topologies of their PDOS. A scheme of the local structure is given that includes atoms for which the PDOS is shown. c) PDOS for Vanadium and its $3 d$ states (V1), then on d) the PDOS of its surrounding anions is given (the three oxygen atoms in red have very similar $2 p$ states contributions while the sulfur anion $3 p$ states in black and yellow filled curve contributes differently. S $3 p$ states of the sulfur species within channel 2 (e) and channel 1 (f), showing their contribution just below the Fermi level and thus constituting the top of the VB. The Fermi level is set to 0 . 

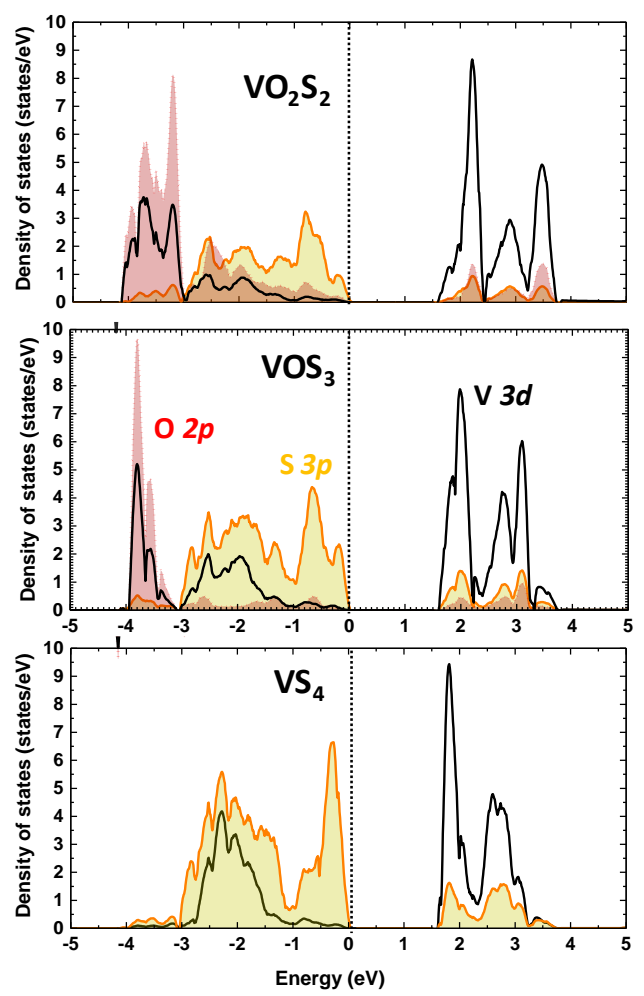

Figure 4. PDOS on the three $T d$ entities $V O_{x} S_{y}$ present in $\mathrm{Ba}_{6} \mathrm{~V}_{4} \mathrm{O}_{5} \mathrm{~S}_{11}$. The $\mathrm{V} 3 d$ states are represented in black. The $2 p$ or $3 p$ contributions are summed per types of anions $\mathrm{O}$ and $\mathrm{S}$, respectively, around $\mathrm{V}^{5+}$ to highlight the effect of the sulfur content on the VBM. The Fermi level is set to 0 .
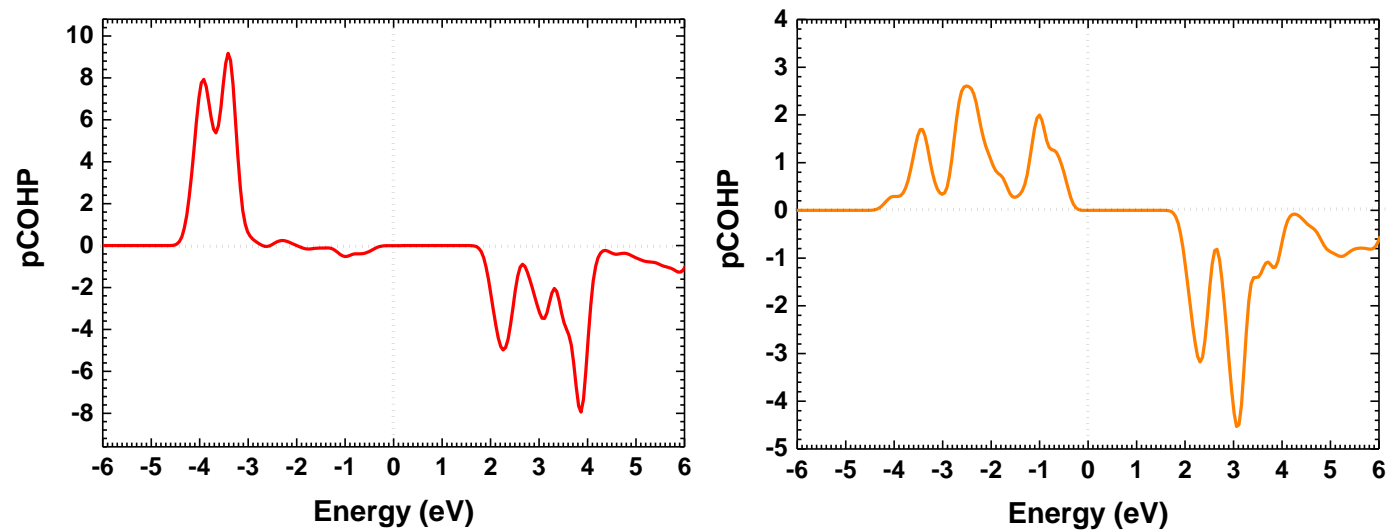

Figure 5. Crystal Orbital Hamilton populations (COHP) of the titled phase for a V-O bond (left) and a V-S bond (right) in the title phase. The Fermi level is set to $0 \mathrm{eV}$. 


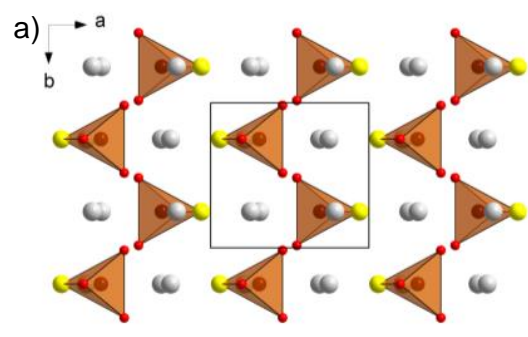

c)

b)


d)

d) $\cdots$

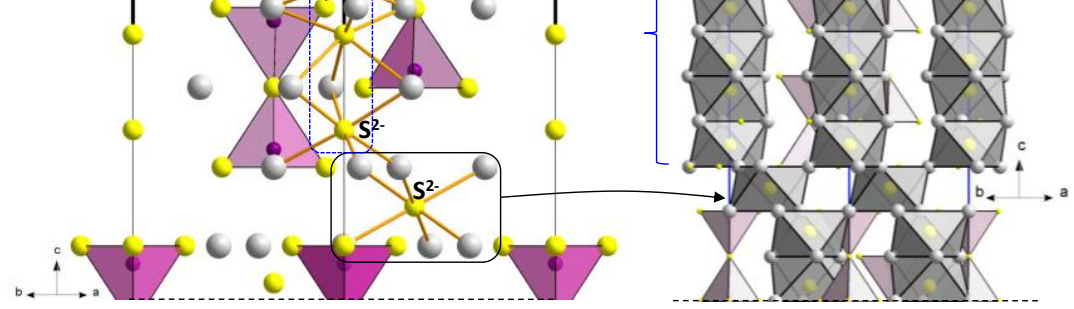

Figure 6. a) Structure of $\mathrm{K}_{3} \mathrm{VO}_{3} \mathrm{~S}$ and b) $\mathrm{Na}_{3} \mathrm{VO}_{3} \mathrm{~S}$, with orange $\mathrm{VO}_{3} \mathrm{~S}$ tetrahedra and $\mathrm{Na} / \mathrm{K}$ atoms in grey. c) Structure of $\mathrm{Ba}_{12} \ln _{4} \mathrm{~S}_{19}$ with $\ln \mathrm{S}_{4}$ tetrahedra in pink, the isolated sulfur $\mathrm{S}^{2-}$ and disulfide pairs are highlighted. d) Here we highlight the face-sharing $\mathrm{Ba}_{6}$ octahedra (in grey) occupied by the later isolated sulfur atoms (in yellow). Broken chains (oligomers) of seven octahedra $\mathrm{SBa}_{6}$ are formed in this phase, octahedra occupied by $\mathrm{S}^{2-}$ anions are alternating with two octahedra, each occupied by one of the two sulfur atoms of a disulfide pair $\left(\mathrm{S}_{2}\right)^{2-}$. Focusing on the $\mathrm{Ba} / \mathrm{S}$ sub-lattice, the oligomers are separated along $c$ by a layer (in the $a b$ plane) of SBa 6 octahedra sharing all their corners with the terminal octahedra of those oligomers.

Table 1. Single crystal XRD refinement data for the title phase $\mathrm{Ba}_{10} \mathrm{~V}_{6} \mathrm{O}_{18} \mathrm{~S}_{7}$

\begin{tabular}{|c|c|}
\hline \multicolumn{2}{|l|}{ Crystal ( $T=298 \mathrm{~K})$} \\
\hline Formula & $\mathrm{Ba}_{10} \mathrm{~V}_{6} \mathrm{O}_{18} \mathrm{~S}_{7}$ \\
\hline Molar Weight (g.mol ${ }^{-1}$ ) & 2191.4 \\
\hline Space group & $P 6_{3}$ \\
\hline \multirow[t]{2}{*}{ Unit cell (Å) } & $a=18.2977(6) \AA$ \\
\hline & $c=8.6591(2) \AA$ \\
\hline Volume & $2510.71 \AA^{3}$ \\
\hline Z & 3 \\
\hline \multicolumn{2}{|l|}{ Data collection } \\
\hline Equipment & Bruker D8 XRK900 \\
\hline$\wedge$ (Mo K $\alpha$ (graphite monochromator); Å) & 0.71073 \\
\hline
\end{tabular}




\begin{tabular}{|c|c|}
\hline Density calc. $\left(\mathrm{g} \cdot \mathrm{cm}^{-3}\right)$ & 4.3478 \\
\hline Crystal shape & platelet \\
\hline Crystal dimensions ( $\mu \mathrm{m})$ & $100 \times 50 \times 40$ \\
\hline Color & Orange \\
\hline Scan mode & $\omega, \varphi$ \\
\hline$\theta(\min -\max )\left(^{\circ}\right)$ & $1.29-34.97$ \\
\hline$\mu(\mathrm{mm}-1 ;$ for $\lambda \mathrm{K} \alpha=0.71073 \AA)$ & 13.655 \\
\hline R(int) (\%) & 3.73 \\
\hline \multirow[t]{3}{*}{ Recording reciprocal space } & $-28 \leq h \leq 29$ \\
\hline & $-29 \leq k \leq 29$ \\
\hline & $-13 \leq I \leq 29$ \\
\hline Number of measured reflections & 80555 \\
\hline Nbr of independent reflections & 5942 \\
\hline$(I>3 \sigma(I))$, total $)$ & 5606 \\
\hline \multicolumn{2}{|l|}{ Refinement } \\
\hline Number of refined parameters & 206 \\
\hline Refinement method & Mean squares \\
\hline Weighting scheme & Unit \\
\hline $\mathrm{R} 1(\mathrm{~F})[\mathrm{I}>3 \sigma(\mathrm{I})] / \mathrm{R} 1\left(\mathrm{~F}^{2}\right)$ [all data, \%] & $0.0321 / 0.0346$ \\
\hline $\mathrm{wR} 2\left(\mathrm{~F}^{2}\right)[\mathrm{I}>3 \sigma(\mathrm{I})] / \mathrm{wR} 2\left(\mathrm{~F}^{2}\right)$ [all data, \%] & $0.0321 / 0.0338$ \\
\hline \multicolumn{2}{|l|}{$w=1 /\left(\sigma^{2}\left(F_{o}^{2}\right)+(0.0682 P)^{2}\right)$} \\
\hline \multicolumn{2}{|l|}{ With $P=\left(\max \left(F_{o}^{2}, 0\right)+2 F_{c}^{2}\right) / 3$} \\
\hline GOF & 0.85 \\
\hline $\begin{array}{l}\text { Max/min residual electronic density (e- } \\
\left./ \AA_{3}\right)\end{array}$ & $3.27 /-1.73$ \\
\hline
\end{tabular}

Table 2. Atomic positions for $\mathrm{Ba}_{10} \mathrm{~V}_{6} \mathrm{O}_{18} \mathrm{~S}_{7}$ 


\begin{tabular}{|l|l|l|l|l|l|}
\hline Atom & Wyck & \multicolumn{1}{|c|}{ S.O.F. } & \multicolumn{1}{|c|}{$\mathbf{X}$} & \multicolumn{1}{|c|}{ Y } & \multicolumn{1}{|c|}{ Z } \\
\hline Ba1 & 6c & & $0.24800(5)$ & $0.50252(4)$ & $0.1639(2)$ \\
Ba2 & 6c & & $0.01552(5)$ & $0.33630(6)$ & $0.4594(2)$ \\
Ba3 & 6c & & $0.32789(5)$ & $0.34557(5)$ & $0.4585(2)$ \\
Ba4a & 6c & $0.914(2)$ & $0.58205(6)$ & $0.16668(4)$ & $0.2424(1)$ \\
Ba4b & 6c & $0.086(2)$ & $0.5876(6)$ & $0.1788(4)$ & $0.1725(8)$ \\
Ba5a & 6c & $0.828(2)$ & $0.07914(8)$ & $0.16066(5)$ & $0.7610(1)$ \\
Ba5b & 6c & $0.172(2)$ & $0.0823(3)$ & $0.1656(2)$ & $0.6804(5)$ \\
V1 & 6c & & $0.1924(2)$ & $0.3787(1)$ & $0.7440(3)$ \\
V2 & 6c & & $0.0465(1)$ & $0.5199(2)$ & $0.1805(3)$ \\
V3 & 6c & & $0.1490(2)$ & $0.2893(1)$ & $0.1865(3)$ \\
S1 & 6c & & $0.1438(2)$ & $0.5749(3)$ & $0.3605(4)$ \\
S2 & 6c & & $0.1093(3)$ & $0.2165(2)$ & $0.3952(4)$ \\
S3 & 6c & & $0.2313(3)$ & $0.4646(2)$ & $0.5475(4)$ \\
S4 & 2b & $0.852(12)$ & $2 / 3$ & $1 / 3$ & $0.4501(6)$ \\
S5 & 2a & $0.648(12)$ & 0 & 0 & $0.0130(6)$ \\
O1 & 6c & & $0.1251(11)$ & $0.2087(10)$ & $0.0460(11)$ \\
O2 & 6c & & $0.1039(7)$ & $0.3493(8)$ & $0.179(2)$ \\
O3 & 6c & & $0.2511(6)$ & $0.3549(7)$ & $0.1805(16)$ \\
O4 & 6c & & $0.2298(7)$ & $0.3091(6)$ & $0.726(2)$ \\
O5 & 6c & & $0.0863(9)$ & $0.3179(10)$ & $0.746(3)$ \\
O6 & 6c & & $0.2493(8)$ & $0.4407(6)$ & $0.8958(10)$ \\
O7 & 6c & & $-0.0126(8)$ & $0.5633(7)$ & $0.183(2)$ \\
O8 & 6c & & $-0.0211(6)$ & $0.4158(6)$ & $0.208(2)$ \\
O9 & 6c & & $0.0963(6)$ & $0.5139(7)$ & $0.0136(12)$ \\
\hline
\end{tabular}

Table 3. Anisotropic thermal parameters $\left(\AA^{2}\right)$ for $\mathrm{Ba}_{10} \mathrm{~V}_{6} \mathrm{O}_{18} \mathrm{~S}_{7}$

\begin{tabular}{|l|c|c|c|c|c|c|}
\hline \multicolumn{1}{|c|}{ Atom } & U11 & U22 & U33 & U12 & U13 & U23 \\
\hline Ba1 & $0.0242(3)$ & $0.0131(2)$ & $0.0165(2)$ & $0.0086(3)$ & $-0.0028(4)$ & $-0.0003(2)$ \\
Ba2 & $0.0229(3)$ & $0.0479(4)$ & $0.0140(3)$ & $0.0184(3)$ & $0.0010(3)$ & $-0.0022(5)$ \\
Ba3 & $0.0294(3)$ & $0.0375(4)$ & $0.0139(2)$ & $0.0220(4)$ & $-0.0003(4)$ & $-0.0006(5)$ \\
Ba4a & $0.0244(3)$ & $0.0116(2)$ & $0.0155(3)$ & $0.0064(3)$ & $-0.0011(4)$ & $-0.0027(2)$ \\
Ba4b & $0.0244(3)$ & $0.0116(2)$ & $0.0155(3)$ & $0.0064(3)$ & $-0.0011(4)$ & $-0.0027(2)$ \\
Ba5a & $0.0242(4)$ & $0.0138(2)$ & $0.0360(5)$ & $0.0073(3)$ & $0.0043(5)$ & $0.0007(3)$ \\
Ba5b & $0.0242(4)$ & $0.0138(2)$ & $0.0360(5)$ & $0.0073(3)$ & $0.0043(5)$ & $0.0007(3)$ \\
V1 & $0.035(1)$ & $0.0124(6)$ & $0.0138(6)$ & $0.0082(8)$ & $0.009(1)$ & $0.0003(5)$ \\
V2 & $0.0131(6)$ & $0.027(1)$ & $0.0232(7)$ & $0.0063(8)$ & $-0.0004(6)$ & $0.002(1)$ \\
V3 & $0.024(1)$ & $0.0147(6)$ & $0.0393(9)$ & $0.0084(8)$ & $-0.001(1)$ & $-0.0028(6)$ \\
S1 & $0.029(1)$ & $0.031(2)$ & $0.026(1)$ & $0.019(2)$ & $-0.0090(9)$ & $-0.006(1)$ \\
S2 & $0.037(2)$ & $0.0387(1)$ & $0.045(2)$ & $0.022(2)$ & $0.011(2)$ & $0.021(1)$ \\
S3 & $0.031(2)$ & $0.026(1)$ & $0.024(1)$ & $0.016(1)$ & $-0.005(2)$ & $0.0085(9)$ \\
S4 & $0.0093(8)$ & $0.0093(8)$ & $0.012(1)$ & $0.0046(4)$ & 0.00000 & 0.00000 \\
S5 & $0.008(1)$ & $0.008(1)$ & $0.022(2)$ & $0.0039(6)$ & 0.00000 & 0.00000 \\
O1 & $0.20(2)$ & $0.13(1)$ & $0.023(4)$ & $0.15(1)$ & $-0.046(7)$ & $-0.046(6)$ \\
\hline
\end{tabular}




\begin{tabular}{|l|l|l|l|l|l|c|}
\hline O2 & $0.011(4)$ & $0.041(6)$ & $0.068(9)$ & $0.015(4)$ & $0.002(5)$ & $0.026(7)$ \\
O3 & $0.024(4)$ & $0.046(6)$ & $0.052(7)$ & $0.028(5)$ & $0.026(5)$ & $0.044(6)$ \\
O4 & $0.015(4)$ & $0.009(3)$ & $0.09(1)$ & $0.000(3)$ & $-0.005(6)$ & $-0.001(5)$ \\
O5 & $0.033(7)$ & $0.052(8)$ & $0.10(1)$ & $0.027(6)$ & $0.038(8)$ & $0.037(9)$ \\
O6 & $0.076(8)$ & $0.013(3)$ & $0.007(3)$ & $-0.005(4)$ & $-0.002(4)$ & $-0.002(3)$ \\
O7 & $0.034(6)$ & $0.021(5)$ & $0.09(1)$ & $0.015(4)$ & $-0.044(7)$ & $-0.008(6)$ \\
O8 & $0.015(4)$ & $0.012(4)$ & $0.09(1)$ & $0.009(3)$ & $-0.018(5)$ & $-0.026(5)$ \\
O9 & $0.025(4)$ & $0.050(6)$ & $0.029(4)$ & $0.009(3)$ & $0.010(4)$ & $-0.003(4)$ \\
\hline
\end{tabular}

Table 4. Comparison of the refined and optimized distances $(\AA \AA)$, the discrepancy from the experimental distances is given (\%).

\begin{tabular}{|c|c|c|c|}
\hline & $\mathrm{Ba}_{5} \mathrm{~V}_{3} \mathrm{O}_{9} \mathrm{~S}_{3.5}$ refined & $\mathrm{Ba}_{5} \mathrm{~V}_{3} \mathrm{O}_{9} \mathrm{~S}_{3.5}$ optimized & \% discrepancy \\
\hline a $(\AA)$ & 18.2977 & 18.6550 & 1.95 \\
\hline$c(\AA)$ & 8.6591 & 8.6994 & 0.46 \\
\hline d S4,Ba1 (Å) & $3.193(3)$ & 3.2616 & 2.15 \\
\hline d S4,Ba4 (Å) & $3.195(3)$ & 3.2541 & 1.84 \\
\hline d S5,Ba5 (Å) & $2.998(4)$ & 3.2946 & 9.90 \\
\hline d V1,06 (Å) & $1.708(9)$ & 1.7125 & 0.25 \\
\hline d V1,04 (Å) & $1.728(2)$ & 1.7195 & 0.47 \\
\hline d V1,05 (Å) & $1.687(1)$ & 1.7271 & 2.36 \\
\hline d V1,S3 (Å) & $2.180(4)$ & 2.2005 & 0.95 \\
\hline d V2,07 (Å) & $1.631(2)$ & 1.7100 & 4.82 \\
\hline d V2,08 (Å) & $1.690(9)$ & 1.7247 & 2.04 \\
\hline d V2,09 (Å) & $1.741(2)$ & 1.7280 & 0.74 \\
\hline $\mathrm{d}$ V2,S1 (Å) & $2.195(4)$ & 2.2036 & 0.39 \\
\hline d V3,O1 (Å) & $1.790(2)$ & 1.7129 & 4.29 \\
\hline d V3,O2 (Å) & $1.672(2)$ & 1.7142 & 2.54 \\
\hline d V3,O3 (Å) & $1.640(9)$ & 1.7082 & 4.13 \\
\hline d V3,S2 (Å) & $2.145(4)$ & 2.2025 & 2.68 \\
\hline
\end{tabular}




\section{REFERENCES}

(1) Takahashi, H.; Igawa, K.; Arii, K.; Kamihara, Y.; Hirano, M.; Hosono, H. Superconductivity at $43 \mathrm{~K}$ in an Iron-Based Layered Compound LaO1-XFxFeAs. Nature 2008, 453, 376-378.

(2) Clarke, S. J.; Adamson, P.; Herkelrath, S. J. C.; Rutt, O. J.; Parker, D. R.; Pitcher, M. J.; Smura, C. F. Structures, Physical Properties, and Chemistry of Layered Oxychalcogenides and Oxypnictides. Inorg. Chem. 2008, 47 (19), 8473-8486.

(3) Freelon, B.; Liu, Y. H.; Chen, J.-L.; Craco, L.; Laad, M. S.; Leoni, S.; Chen, J.; Tao, L.; Wang, H.; Flauca, R.; et al. Mott-Kondo Insulator Behavior in the Iron Oxychalcogenides. Phys. Rev. B 2015, 92 (15), 155139.

(4) Yang, D.; Su, X.; Yan, Y.; Hu, T.; Xie, H.; He, J.; Uher, C.; Kanatzidis, M. G.; Tang, X. Manipulating the Combustion Wave during Self-Propagating Synthesis for High Thermoelectric Performance of Layered Oxychalcogenide Bi1-XPbxCuSeO. Chem. Mater. 2016, 28 (13), 4628-4640.

(5) Jiang, G.; Wei, X.; Chen, Y.; Duan, C.; Yin, M.; Yang, B.; Cao, W. Luminescent La2O2S:Eu3+ Nanoparticles as Non-Contact Optical Temperature Sensor in Physiological Temperature Range. Mater. Lett. 2015, 143, 98-100.

(6) Zhang, J.-C.; Zhao, L.-Z.; Long, Y.-Z.; Zhang, H.-D.; Sun, B.; Han, W.-P.; Yan, X.; Wang, X. Color Manipulation of Intense Multiluminescence from CaZnOS:Mn2+ by Mn2+ Concentration Effect. Chem. Mater. 2015, 27 (21), 7481-7489.

(7) Wang, X.; Zhu, Q.; Li, J.-G.; Hu, Z.; Zhu, G.; Wang, C. La2O2S:Tm/Yb as a Novel Phosphor for Highly Pure near-Infrared Upconversion Luminescence. Scr. Mater. 2018, $149,121-124$.

(8) Hakmeh, N.; Chlique, C.; Merdrignac-Conanec, O.; Fan, B.; Cheviré, F.; Zhang, X.; Fan, X.; Qiao, X. Combustion Synthesis and Up-Conversion Luminescence of La2O2S:Er3+,Yb3+ Nanophosphors. J. Solid State Chem. 2015, 226, 255-261.

(9) Liu, B.-W.; Jiang, X.-M.; Wang, G.-E.; Zeng, H.-Y.; Zhang, M.-J.; Li, S.-F.; Guo, W.-H.; Guo, G.-C. Oxychalcogenide BaGeOSe2 : Highly Distorted Mixed-Anion Building Units Leading to a Large Second-Harmonic Generation Response. Chem. Mater. 2015, 27 (24), 8189-8192. 
(10) Schnabel, S.; Röhr, C. Kalium-Thio/Oxo-Vanadate(V) K3[VSxO4 - x] (x=1-4) Und Na3[VSO3]: Synthese, Strukturchemie, Eigenschaften. Z. Naturforsch 2008, 63, 819833.

(11) Schnabel, S.; Röhr, C. Gemischte Thio/Oxo-Orthovanadate Na3[VSxO4 -x] $(x=2,3)$ : Darstellung - Strukturen - Eigenschaften. Z. Naturforsch. 2005, 60b (5), 479-490.

(12) a) Hopkins, E. J.; Prots, Y.; Burkhardt, U.; Watier, Y.; Hu, Z.; Kuo, C.-Y.; Chiang, J.-C.; Pi, T.-W.; Tanaka, A.; Tjeng, L. H.; et al. Ba3V2S4O3 : A Mott Insulating Frustrated QuasiOne-Dimensional S =1 Magnet. Chem. - A Eur. J. 2015, 21 (21), 7938-7943. b) Kim, J.; Lai, K. T.; Valldor, M. Magnetism on quasi-1-D lattices in novel non-centrosymmetric $\mathrm{Ba}_{3} \mathrm{CrVS}_{4} \mathrm{O}_{3}$ and in centrosymmetric $\mathrm{La}_{3} \mathrm{TMWS}_{3} \mathrm{O}_{6}(\mathrm{TM}=\mathrm{Cr}, \mathrm{Fe}, \mathrm{Co})$. J. Mag. Mag. Mat. 2017, 435,126-135

(13) Gulay, L. D.; Lychmanyuk, O. S.; Wołcyrz, M.; Pietraszko, A.; Olekseyuk, I. D. The Crystal Structures of R3CuGeS7 ( $\mathrm{R}=\mathrm{Ce}-\mathrm{Nd}, \mathrm{Sm}, \mathrm{Gd}-\mathrm{Dy}$ and Er). J. Alloys Compd. 2006, 425 (1-2), 159-163.

(14) Kresse, G.; Joubert, D. From Ultrasoft Pseudopotentials to the Projector AugmentedWave Method. Phys. Rev. B 1999, 59 (3), 1758-1775.

(15) Blöchl, P. E. Projector Augmented-Wave Method. Phys. Rev. B 1994, 50 (24), 1795317979.

(16) G.Kresse, J. F. Vienna Ab-Initio Simulation Package (VASP). Institut für Materialphysik: Vienna. 2012.

(17) Perdew, J. P.; Burke, K.; Ernzerhof, M. Generalized Gradient Approximation Made Simple. Phys. Rev. Lett. 1996, 77 (18), 3865-3868.

(18) Maintz, S.; Deringer, V. L.; Tchougréeff, A. L.; Dronskowski, R. LOBSTER: A Tool to Extract Chemical Bonding from Plane-Wave Based DFT. J. Comput. Chem. 2016, 37 (11), 1030-1035.

(19) Deringer, V. L.; Tchougréeff, A. L.; Dronskowski, R. Crystal Orbital Hamilton Population (COHP) Analysis As Projected from Plane-Wave Basis Sets. J. Phys. Chem. A 2011, 115 (21), 5461-5466.

(20) Dronskowski, R.; Bloechl, P. E. Crystal Orbital Hamilton Populations (COHP): EnergyResolved Visualization of Chemical Bonding in Solids Based on Density-Functional Calculations. J. Phys. Chem. 1993, 97 (33), 8617-8624.

(21) Petříček, V.; Dušek, M.; Palatinus, L. Crystallographic Computing System JANA2006: 
General Features. Zeitschrift für Krist. - Cryst. Mater. 2014, 229 (5), 345-352.

(22) Schnabel, S.; Röhr, C. Kalium-Thio/Oxo-Vanadate(V) $\mathrm{K}_{3}\left[\mathrm{VS}_{\mathrm{x}} \mathrm{O}_{4-\mathrm{x}}\right](\mathrm{x}=1-4)$ und $\mathrm{Na}_{3}\left[\mathrm{VSO}_{3}\right]$ : Synthese, Strukturchemie, Eigenschaften. Z. Naturforsch. 2008, 63b, 819833.

(23) Jenks, J. M.; Hoggins, J. T.; Rendon-DiazMiron, L. E.; Cohen, S.; Steinfink, H. Octahedrally Coordinated Iron in the Barium-Iron-Sulfur System: Ba9Fe3S11(S2)2, a High-Pressure Polymorph of Ba3FeS5. Inorg. Chem. 1978, 17 (7), 1773-1775.

(24) Dolgos, M. R.; Paraskos, A. M.; Stoltzfus, M. W.; Yarnell, S. C.; Woodward, P. M. The Electronic Structures of Vanadate Salts: Cation Substitution as a Tool for Band Gap Manipulation. J. Solid State Chem. 2009, 182 (7), 1964-1971.

(25) Wendlandt, W.; Hecht, H. G. Reflectance Spectroscopy; 1966.

(26) Liu, J.-W.; Wang, P.; Chen, L. Contribution of Disulfide S22-Anions to the Crystal and Electronic Structures in Ternary Sulfides, Ba12In4S19, Ba4M2S8 (M = Ga, In). Inorg. Chem. 2011, 50 (12), 5706-5713.

(27) Driss, D.; Cadars, S.; Deniard, P.; Mevellec, J.-Y.; Corraze, B.; Janod, E.; Cario, L. Crystal Structure and Chemical Bonding in the Mixed Anion Compound BaSF. Dalt. Trans. 2017, 46 (46), 16244-16250. 


\section{For Table of Contents Only}

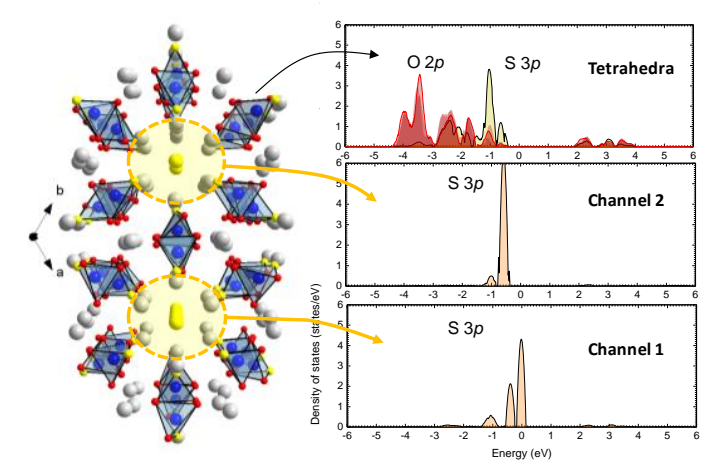

\section{Synopsis :}

The new oxysulfide $\mathrm{Ba}_{10} \mathrm{~V}_{6} \mathrm{~S}_{7} \mathrm{O}_{18}$, that can be written $\mathrm{Ba}_{10} \mathrm{~S}\left(\mathrm{VO}_{3} \mathrm{~S}\right)_{6}$, crystallizes in the noncentrosymmetric $P 6_{3}$ space group in an original structural type with $\left(\mathrm{VO}_{3} \mathrm{~S}\right)$ mixed anion units separated by $\mathrm{Ba}^{2+}$ cations delimiting 2 types of deficient channels filled with isolated sulfur $\mathrm{S}^{2-}$ anions. DFT calculations show that the later contribute strongly just below the fermi level with subsequent alteration of the band gap. Design of systems with adjusted band gap features should arises from this work. 